\title{
Burnout syndrome in Spanish medical students
}

\author{
Javier Gil-Calderón ${ }^{1 \dagger}$, Jéssica Alonso-Molero ${ }^{2,3^{* \dagger}}$, Trinidad Dierssen-Sotos ${ }^{2,3}$, Inés Gómez-Acebo ${ }^{2,3}$ and \\ Javier Llorca ${ }^{1,3}$
}

\begin{abstract}
Background: Burnout syndrome is a frequent syndrome related to people that feel a deterioration in their daily activities due to highly demandant psychological requirements in their workplaces. Within last decades, this syndrome has been studied across medical professionals, concluding that stress levels that physicians suffer is high enough to make them develop burnout syndrome. In the case of medical students, there are some recent studies, although with small samples. For this reason, given that this phenomenon may produce a huge impact in medical students' development, the aim of this study is to analyze the influential factors that may contribute to its occurrence.

Methods: The necessary information was gathered through a web-based questionnaire, divided in two parts. The first part of the survey included questions related to personal aspects of the students. Burnout related questions (second part) were divided in three subscales to evaluate exhaustion, cynicism, and academic efficacy levels.

Results: Family support for studying medicine is associated with lower burnout levels in all three scales of the Maslach Burnout Inventory. The number of years spent in the degree show the opposite trend: the more years in the degree, the higher score in all burnout scales.

Conclusions: Burnout syndrome is a problem among medical students in Spain that increases with the number of years studying medicine. It should be also noticed that family support and vocational studies are independent factors related to lower levels of burnout.
\end{abstract}

Keywords: Burnout, Medical student, Family support, Maslach burnout inventory

\section{Introduction}

Burnout syndrome is increasingly frequent and is related to people that suffer a deterioration in their daily activities due to highly demandant psychological requirements in their workplaces [1]. Freudenberger described burnout syndrome as the stress suffered by those people who work in contact with other people [2]. Maslach and

\footnotetext{
* Correspondence: alonsomoleroj@gmail.com

†Javier Gil-Calderón and Jéssica Alonso-Molero contributed equally to this work.

${ }^{2}$ Universidad de Cantabria - IDIVAL, Avda. Herrera Oria s/n, 39011 Santander, Cantabria, Spain

${ }^{3}$ CIBER Epidemiología y Salud Pública (CIBERESP), Madrid, Spain

Full list of author information is available at the end of the article
}

Jackson gave its definitive definition as a syndrome of emotional exhaustion and cynicism that occurs frequently among individuals who do "people-work" of some kind [3].

Within last decades, burnout syndrome has been studied across medical professionals, concluding that physicians suffer stress levels high enough to make them develop it $[1,4,5]$. In the last years, attention has also been paid to the presence of the burnout syndrome in medical students [6-9]. However, most of these studies have relatively small student participation $[8,9]$, which makes it necessary to increase research in this field.

(c) The Author(s). 2021 Open Access This article is licensed under a Creative Commons Attribution 4.0 International License, which permits use, sharing, adaptation, distribution and reproduction in any medium or format, as long as you give appropriate credit to the original author(s) and the source, provide a link to the Creative Commons licence, and indicate if changes were made. The images or other third party material in this article are included in the article's Creative Commons licence, unless indicated otherwise in a credit line to the material. If material is not included in the article's Creative Commons licence and your intended use is not permitted by statutory regulation or exceeds the permitted use, you will need to obtain permission directly from the copyright holder. To view a copy of this licence, visit http://creativecommons.org/licenses/by/4.0/ The Creative Commons Public Domain Dedication waiver (http://creativecommons.org/publicdomain/zero/1.0/) applies to the data made available in this article, unless otherwise stated in a credit line to the data. 
When it comes to speak about students, burnout syndrome is defined as lack of concentration, inability to focus, difficulty in retaining information, experiencing recurrent headaches, lack of sleep, feeling fatigued and helpless, not putting up the best efforts, and experiencing unknown hesitation due to academic stressors and performance anxiety [6]. Students, especially those that are enrolled at University, are frequently immersed in situations, activities and academic events that generate stress and anxiety, like compulsory presentations, lack of time and task overload [3]. In such way, when the exposition to the stressors is produced habitually and students lack strategies to confront it properly, academic burnout syndrome may appear [3]. These students would show high levels of emotional tiredness or exhaustion, cynicism about their studies, and low efficacy in the development of academic activities [3].

Maslach Burnout Inventory (MBI; Maslach y Jackson, 1986) [3] is the validated survey to test the burnout syndrome in health care professional, whereas Schaufeli, Martínez, Pinto, y Salanova, 2002 adapted it for students [7]. Their questionnaire tests the feelings and attitudes of students to their academic activity, using 15 items grouped into three subscales (emotional exhaustion, depersonalization and academic efficacy).

Given that this phenomenon may produce a huge impact in medical students' development, it is relevant to study the risk factors of this syndrome within this collective, in order to develop strategies that may improve the symptoms and reduce the consequences. Having explained that and knowing the fact that the search developed until now contemplates comparatively small samples, the aim of this study is to analyze the influential factors that may contribute to the presence of burnout symptoms in medical students in a sample of 1073 medicine students.

\section{Methods}

\section{Setting and participants}

This project was designed as a cross sectional study based on the results obtained from the MBI-SS (Maslach Burnout Inventory-Student Survey) conducted between April and May of 2019, given to medical students from all over Spain. The survey was targeted to medical students from the first year to the last one (in Spain, the Medicine Degree lasts for 6 years).

The target population was reached by sending the survey to the CEEM (Spanish Medical Students Council), that distributed it within the Medical Faculties in Spain. Student representants of the Faculties do not participating in CEEM were independently contacted to distribute the survey. Students from 32 out of the 42 Medical Faculties in Spain were reached and filled the survey.
The only inclusion criterium was to be a medical student appointed in any Medical School in Spain, without any exclusion criteria.

\section{Gathered information}

The information was gathered through a web-based questionnaire including questions about the personal situation of the participants and the MBI-SS [7]. This survey was anonymous, and the complete survey employed is in the Additional files 1 and 2.

The first part of the survey included questions related to personal aspects of the students as gender, age, vocation for medicine when entering in the Faculty (yes / no), family support for studying medicine, (i.e. how the students feel that their families back up that they are studying medicine. In a Likert scale from 1 -no supportto 10 -maximum support), year of the medical degree, number of years since entering in the Medicine Faculty (detailed in Additional file 1).

Burnout related questions were divided in three subscales which contained several questions each, as MBISS recommend. These three subscales evaluate exhaustion, cynicism and academic efficacy levels, and their questions (detailed in Additional file 2) were meant to be answered from 1 (completely disagree) to 10 (completely agree) according with the degree of agreement with the affirmations given.

\section{Ethical issues}

The research was approved by the University of Cantabria Ethics Committee (code: CE TFG 03/2019) and was conducted according with the Spanish laws on medical research, the European Union regulations on general data protection of natural persons with regard to the processing of personal data and the Declaration of Helsinki. Regulation (EU) 2016/679 of the European Parliament and of the Council of 27 April 2016 on the protection of natural persons with regard to the processing of personal data and on the free movement of such data, and repealing Directive 95/46/EC. Available at https:// op.europa.eu/en/publication-detail/-/publication/3e485 e15-11bd-11e6-ba9a-01aa75ed71a1/ (accessed 04/10/19). All participants signed an informed consent.

\section{Statistical analysis}

Firstly, all questions in the Maslach Burnout Inventory were rescaled to 1-7 in order to make them comparable with the original questionnaire. Questions related to academic efficacy were inverted as they were positive, whereas the affirmations in the other subscales were negative. After inverting academic efficacy subscale, all questions scored in the same way: the higher the scale, the higher the burn-out. Then, three scores were created by adding up the punctuation scored in each question of 
Table 1 Results of burnout scales

\begin{tabular}{lll}
\hline & Mean $\pm \mathbf{s d}$ & Median (IQR) \\
\hline Depersonalization & $14.83 \pm 7.09$ & $14.1(8.67-19.56)$ \\
Exhaustion & $27.50 \pm 7.16$ & $28.3(22.89-33.00)$ \\
Academic Efficacy & $22.38 \pm 6.89$ & $22.3(17.67-26.22)$ \\
\hline
\end{tabular}

each subscale: (1) Exhaustion score (how tired students feel during the development of their daily academic activities); it includes 5 questions so it could score from 5 to 40. (2) Depersonalization score (how sceptic students feel about the importance of their studies); it includes 4 questions, so it could score from 4 to 32 . And (3) academic efficacy score (how effective students feel developing their daily academic activities); it is obtained by adding the answers to 6 questions; it could score from 6 to 48 .

Student $t$ test was used to relate the burnout levels with gender and vocation, whereas ANOVA test was used to relate the burnout level with age, year of the degree, number of years in the degree and family support. Finally, multiple linear regression models were used to analyze which of these factors influence the score in each burnout subscale.

The statistical analysis was carried out with the software Stata/SE 16.

\section{Results}

One thousand and seventy-three students answered the survey. Descriptive data relating to personal information can be found in Additional file 3. Almost 75\% participants were women, nearly $88 \%$ participants felt vocation for medical studies, and $85 \%$ participants felt high family support for studying medicine. About $86 \%$ students were less than 24 years old, most people (63\%) who answered the survey were between third and fifth year and $87 \%$ students answering the survey had been studying medicine for 5 years or less.

The five medical schools with more answers to the survey were the University of Cantabria $(n=197)$, the University of Alcala $(n=173)$, the University of Navarra $(n=154)$, the University of Barcelona $(n=86)$, and the University of Granada $(n=72)$.

Burnout subscales means \pm standard deviations were $14.8 \pm 7.1$ for depersonalization, $27.5 \pm 7.2$ for exhaustion and $22.4 \pm 6.9$ for academic efficacy, as displayed in Table 1 . They were all three positively correlated with each other (Additional file 4).

Table 2 displays the association between burnout scales and categorical variables. Women reported higher levels of exhaustion, while students declaring to study medicine due to vocation reported lower levels of burnout in depersonalization and academic efficacy scales. The year of the medical degree correlated positively with higher levels of exhaustion and depersonalization, and negatively with academic efficacy levels.

Age and number of years studying the medical degree were related to higher levels of burnout in the three scores (Fig. 1a and b, respectively), and family support protects against higher levels of burnout in the three subscales (Fig. 1c).

Table 3 shows the results of the multiple regression carried out between the personal variables and the three subscales of burnout. Relating to exhaustion subscale, women scored 2.33 points more on average $(95 \% \mathrm{CI}$ : $1.23-3.44, p<0.001$ ), each year studying medicine increased exhaustion by 1.20 points (95\% CI: $0.39-2.01$, $p=0.004)$ and family support for studying medicine decreased exhaustion by 0.4 points $(95 \% \mathrm{CI}:-0.64--0.15$, $p=0.002$ ). The remaining variables (age, year of the degree and vocation when entering the degree) were far from statistically significant.

Table 2 Categorical variables associated with burnout levels

\begin{tabular}{|c|c|c|c|c|c|c|c|c|}
\hline \multirow[t]{3}{*}{ Variable } & \multirow[t]{3}{*}{ Category } & \multirow[t]{3}{*}{$\mathrm{n}$} & \multicolumn{6}{|c|}{ Burnout Levels } \\
\hline & & & \multicolumn{2}{|l|}{ Exhaustion } & \multicolumn{2}{|c|}{ Depersonalization } & \multicolumn{2}{|c|}{ Academic Efficacy } \\
\hline & & & Mean \pm Sd & $p$ & Mean \pm Sd & $p$ & Mean \pm Sd & $\mathrm{p}$ \\
\hline \multirow[t]{2}{*}{ Sex } & Male & 266 & $22.8 \pm 6.7$ & $<0.001$ & $13.6 \pm 6.6$ & 0.07 & $19.2 \pm 6.6$ & 0.25 \\
\hline & Female & 804 & $24.4 \pm 6.0$ & & $12.8 \pm 6.0$ & & $19.7 \pm 5.9$ & \\
\hline \multirow[t]{2}{*}{ Vocation } & No & 130 & $24.7 \pm 6.2$ & 0.27 & $14.6 \pm 6.5$ & 0.001 & $21.3 \pm 6.4$ & $<0.001$ \\
\hline & Yes & 943 & $24.0 \pm 6.3$ & & $12.8 \pm 6.1$ & & $19.3 \pm 6.5$ & \\
\hline \multirow[t]{6}{*}{ Year of the medical degree } & 1 & 167 & $22.3 \pm 6.1$ & $<0.001$ & $10.0 \pm 5.2$ & $<0.001$ & $18.6 \pm 5.6$ & 0.002 \\
\hline & 2 & 123 & $22.7 \pm 6.2$ & & $11.9 \pm 6.0$ & & $19.5 \pm 6.6$ & \\
\hline & 3 & 225 & $23.7 \pm 6.0$ & & $12.0 \pm 5.6$ & & $18.7 \pm 5.8$ & \\
\hline & 4 & 200 & $24.7 \pm 6.2$ & & $14.1 \pm 6.4$ & & $20.7 \pm 5.9$ & \\
\hline & 5 & 254 & $25.4 \pm 6.1$ & & $14.6 \pm 6.4$ & & $20.3 \pm 6.1$ & \\
\hline & 6 & 104 & $25.0 \pm 6.5$ & & $15.1 \pm 6.2$ & & $19.6 \pm 6.2$ & \\
\hline
\end{tabular}




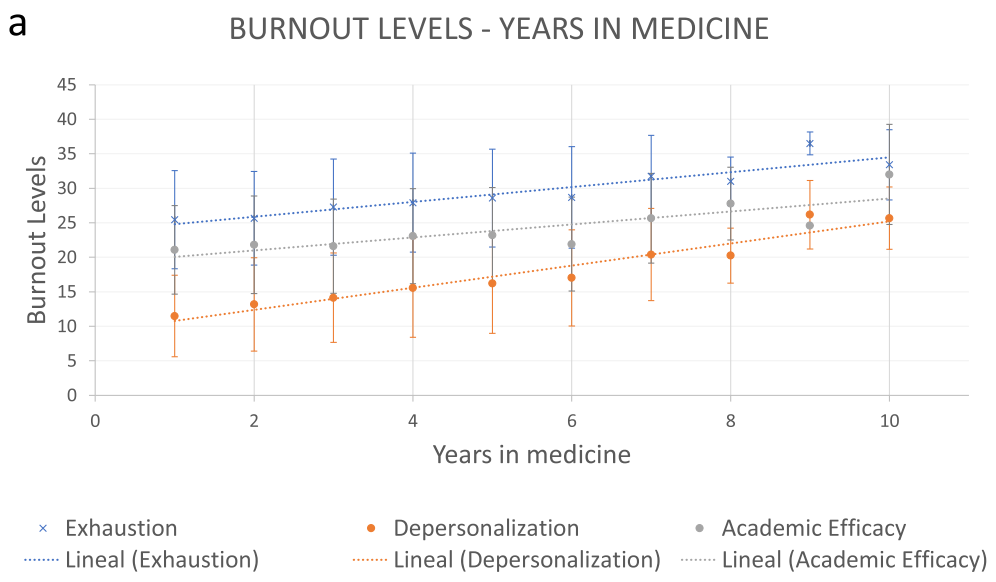

b

AGE - BURNOUT LEVELS

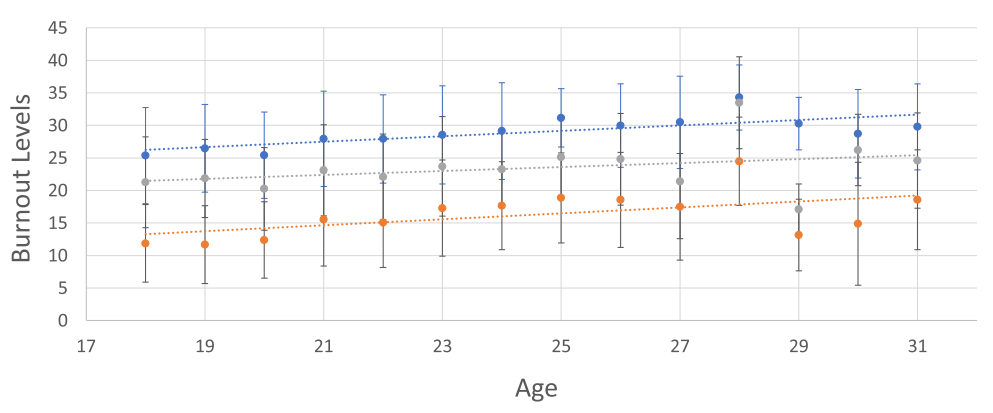

- Exhaustion

- Depersonalization

- Academic Efficacy

....... Lineal (Exhaustion

....... Lineal (Depersonalization)

..... Lineal (Academic Efficacy)

C

Familiar Support - Burnout
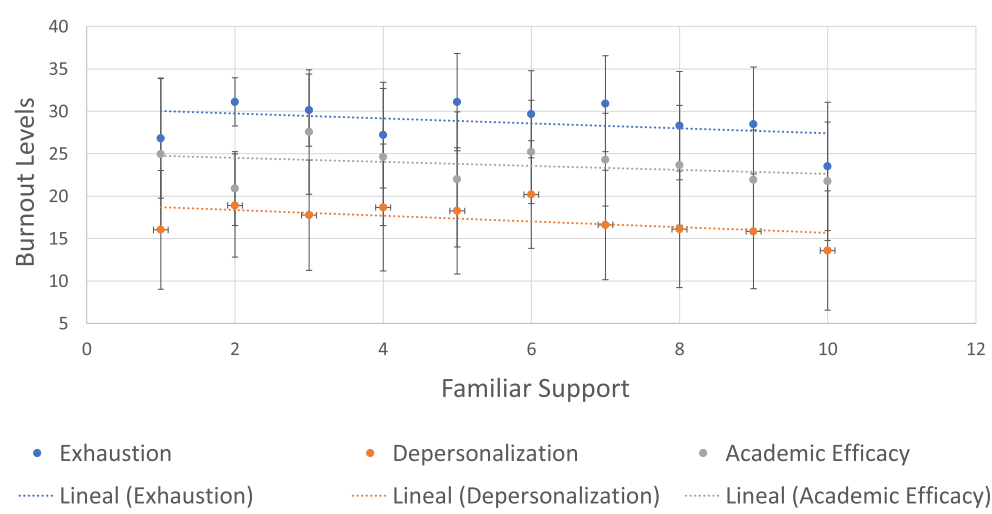

Familiar Support

......... Lineal (Exhaustion)

- Depersonalization

- Academic Efficacy

Lineal (Depersonalization)

.. Lineal (Academic Efficacy)

Fig. 1 Association between burnout scales and number of years studying the medical degree (a), age (b) and family support (c)

Number of years studying medicine was also associated with higher levels of depersonalization burnout (1.64 points more per year, $95 \% \mathrm{CI}$ : 0.87-2.41, $p<0.001$ ), while family support $(-0.59$ points, $95 \%$ CI: $-0.83--0.35$, $\mathrm{p}<0.001)$ and vocational studies $(-2.09$ points, $95 \% \mathrm{CI}$ : $-3.49--0.69, \mathrm{p}=0.004)$ decreased depersonalization.
Regarding academic efficacy burnout, number of years studying medicine was the only factor associated with higher burnout level (1.78 points per year, $95 \%$ CI: 1.01$2.56, \mathrm{p}<0.001)$ while year of the degree $(-1.60$ points per year, $95 \%$ CI: $-2.45--0.85, p<0.001$ ), family support $(-0.46$ points, $95 \% \mathrm{CI}:-0.72--0.24, \mathrm{p}<0.001)$ and 
Table 3 Factors that influence exhaustion, depersonalization, and academic efficacy subscales

\begin{tabular}{|c|c|c|c|c|c|c|c|c|c|c|c|c|}
\hline \multirow[b]{3}{*}{ Age } & \multicolumn{4}{|c|}{ Exhaustion } & \multicolumn{4}{|c|}{ Depersonalization } & \multicolumn{4}{|c|}{ Academic efficacy } \\
\hline & \multirow{2}{*}{$\begin{array}{l}\text { Coef. } \\
0.15\end{array}$} & \multicolumn{2}{|c|}{$95 \% \mathrm{Cl}$} & \multirow{2}{*}{$\begin{array}{l}\boldsymbol{p} \text { value } \\
0.36\end{array}$} & \multirow{2}{*}{$\begin{array}{l}\text { Coef. } \\
0.16\end{array}$} & \multicolumn{2}{|c|}{$95 \% \mathrm{Cl}$} & \multirow{2}{*}{$\begin{array}{l}\boldsymbol{p} \text { value } \\
0.31\end{array}$} & \multirow{2}{*}{$\begin{array}{l}\text { Coef. } \\
0.09\end{array}$} & \multicolumn{2}{|c|}{$95 \% \mathrm{Cl}$} & \multirow{2}{*}{$\frac{p \text { value }}{0.54}$} \\
\hline & & -0.17 & 0.46 & & & -0.15 & 0.46 & & & -0.21 & 0.40 & \\
\hline Woman & 2.33 & 1.23 & 3.44 & $<0.001$ & -0.59 & -1.65 & 0.46 & 0.27 & 0.90 & -0.16 & 1.98 & 0.10 \\
\hline Year of the degree & -0.56 & -1.38 & 0.27 & 0.19 & -0.64 & -1.43 & 0.15 & 0.11 & -1.60 & -2.45 & -0.85 & $<0.001$ \\
\hline Years studying Medicine & 1.20 & 0.39 & 2.01 & 0.004 & 1.64 & 0.87 & 2.41 & $<0.001$ & 1.78 & 1.01 & 2.56 & $<0.001$ \\
\hline Family Support & -0.4 & -0.64 & -0.15 & 0.002 & -0.59 & -0.83 & -0.35 & $<0.001$ & -0.46 & -0.72 & -0.24 & $<0.001$ \\
\hline Vocation & -0.88 & -2.35 & 0.58 & 0.24 & -2.09 & -3.49 & -0.69 & 0.004 & -2.74 & -4.10 & -1.27 & $<0.001$ \\
\hline
\end{tabular}

vocational studies $(-2.74$ points, 95\% CI: $-4.10-$ $1.27, \mathrm{p}<0.001)$ were related to lower levels of burnout.

\section{Discussion}

One of the main results in our study was that the family support for studying medicine is associated with lower burnout levels in all three scales of the Maslach Burnout Inventory, exhaustion, depersonalization and academic efficacy, provoking students that feel higher levels of family support to suffer lower burnout levels. This hypothesis is strengthened by Santen et al. [9] who explain that it is because of family closeness is considered a protective factor that lowers stress and increases happiness. In addition, Santen et al. consider that a good ambient at home, outside of school, helps to the student get away from intense study, evaluations and, the contact with poor prognostic patients [9]. Several studies have also reported that social isolation and vulnerability worsen burnout syndrome, and that strong family relation and a correct motivation provided by relatives ease medical student's performance and protect them $[10,11]$.

On the other hand, the number of years spent in the degree show the opposite trend: the more years in the degree, the higher score in all burnout scales. Previous studies have suggested that burnout levels increased each year of the medical degree [8, 12-15] although those results were not adjusted for the number of years in the degree. In addition, Galán et al. [8] found that the risk of burnout doubled from third year to sixth year in a sample of 270 Spanish medical students.

These results agree with the ones obtained in a multicentric study carried out in Chile among 1395 medical students that showed that 1 out of 2 students suffers burnout syndrome during the degree [16]. Also it is in agreement with Santen et al. results [9], where the authors affirm that one-third of all medical student show a moderate or high degree of burnout, being $43 \%$ of the third-year class. These higher levels of burnout during the development of the medical degree are associated to lower interest for the medical profession [17], which may lead to worse medical performance associated to lower levels of empathy among future physicians [18, 19] that finally leads to worsen medical performance [20]. This is one of the reasons why it has been suggested that burnout in physicians is rooted in their formative period [21].

This study has some limitations such as comparing results about burnout in the literature is not easy mainly due to the difference in the curriculum between the Schools of Medicine (e.g., age at matriculation or number of years studying medicine). Secondly, Bianchi, Schonfeld and Laurent have criticized prevalence estimations for burnout syndrome as Maslach Burnout Inventory scales have no established thresholds for diagnosing burnout [22-24]; therefore, we have avoided any cut-off and present our results in a quantitative scale. However, this procedure makes it difficult any comparison with other studies. Thirdly, about $75 \%$ participants in our study were women, which highly resembles the current sex distribution of medical students in Spanish universities; although according to our and other results, gender seems not to have association to burnout subscales [8], it is problematic to reach a define conclusion on burnout in men, given the relatively small sample of males analyzed. Finally, notice that some authors have questioned the validity of the MBI to assess the burnout syndrome in medical student [22, 25]. However, there are many authors who support its validity [26-28] and Dyrbye et al. considered MBI as "the reference standard for measuring symptoms of burnout" [29]. In fact, MBI is the most applied tool in the worldwide to test this syndrome, being used in more than $90 \%$ of all empirical studies [25].

\section{Conclusions}

Concluding, the results of this article suggest that burnout syndrome is a problem among medical students in Spain that increases with the number of years studying medicine. It should be also noticed that family support and vocational studies are independent factors related to lower levels of burnout. 


\section{Supplementary Information}

The online version contains supplementary material available at https:/doi. org/10.1186/s12909-021-02661-4

Additional file 1. "Personal questions of the survey" and contain the first part of the survey.

Additional file 2. "Burnout questionnaire subscales and questions" and contain the second part of the survey, specific Burnout questionnaire.

Additional file 3. "Sample description" and contain a table whit the sample description.

Additional file 4. "Pearson's correlation coefficient between the burnout scales." and contain a table whit Pearson's correlation coefficient between the burnout scales.

\section{Acknowledgements}

Not applicable.

\section{Authors' contributions}

$J C G, J A M$ and $J L$ have contributed to the conception and design of the study. JCG, JAM and JL have acquired the data and have been involved in drafting the manuscript. The first draft of the manuscript was written by JCG and JAM and TDS, IGA, and JL commented on previous versions of the manuscript. All authors (JCG, JAM, TDS, IGA, and JL) read and approved the final manuscript.

\section{Funding}

Not applicable.

\section{Availability of data and materials}

The datasets generated and/or analysed during the current study are available from the corresponding author on reasonable request.

\section{Declarations}

\section{Ethics approval and consent to participate}

Ethics approval and guidelines:

The research was approved by the University of Cantabria Ethics Committee (code: CE TFG 03/2019) and was conducted according with the Spanish laws on medical research, the European Union regulations on general data protection of natural persons regarding the processing of personal data, and the Declaration of Helsinki.

Regulation (EU) 2016/679 of the European Parliament and of the Council of 27 April 2016 on the protection of natural persons regarding the processing of personal data and on the free movement of such data, and repealing Directive 95/46/EC. Available at https://op.europa.eu/en/publication-detail/-/ publication/3e485e15-11bd-11e6-ba9a-01aa75ed71a1/ (accessed 04/10/19). Informed consent statement:

All participants signed an informed consent.

\section{Consent for publication}

All participants signed an informed consent.

\section{Competing interests}

The authors declare that they have no competing interests.

\section{Author details}

${ }^{1}$ Universidad de Cantabria, Santander, Spain. ${ }^{2}$ Universidad de Cantabria IDIVAL, Avda. Herrera Oria s/n, 39011 Santander, Cantabria, Spain. ${ }^{3} \mathrm{CIBER}$ Epidemiología y Salud Pública (CIBERESP), Madrid, Spain.

Received: 17 December 2020 Accepted: 8 April 2021 Published online: 22 April 2021

\section{References}

1. Panagioti M, Geraghty K, Johnson J, Zhou A, Panagopoulou E, ChewGraham C, et al. Association between physician burnout and patient safety, professionalism, and patient satisfaction: a systematic review and metaanalysis. JAMA Intern Med. 2018;178(10):1317-30. https://doi.org/10.1001/ja mainternmed.2018.3713.
2. Martos Á, Pérez-Fuentes M del C, Molero M del M, Gázquez JJ, Simón M del M, Barragán AB Burnout y engagement en estudiantes de Ciencias de la Salud Eur J Investig Heal Psychol Educ 2018;8:23-36.

3. Maslach C, Jackson SE. The measurement of experienced burnout. J Organ Behav. 1981;2(2):99-113. https://doi.org/10.1002/job.4030020205.

4. Rotenstein LS, Torre M, Ramos MA, Rosales RC, Guille C, Sen S, et al. Prevalence of burnout among physicians a systematic review. JAMA. 2018; 320(11):1131-50. https://doi.org/10.1001/jama.2018.12777.

5. Rich J. A Look in the Mirror: The Role of Medical Training in Physician Burnout. NEJM Catal. 2018:2:4-7.

6. Shoaib M, Afzal A, Aadil M. "Medical students" burn out - need of student mentor and support groups and emotional resilience skills training to be a part of medical school curriculum. Adv Med Educ Pract. 2017;8:179-80. https://doi.org/10.2147/AMEP.S132809.

7. Schaufeli WB, Martínez IM, Pinto AM, Salanova M, Barker AB. Burnout and engagement in university students: a cross-national study. J Cross-Cult Psychol. 2002;33:464-81.

8. Galán F, Sanmartín A, Polo J, Giner L. Burnout risk in medical students in Spain using the Maslach burnout inventory-student survey. Int Arch Occup Environ Health. 2011;84(4):453-9. https://doi.org/10.1007/s00420-011-0623-X.

9. Santen SA, Holt DB, Kemp JD, Hemphill RR. Burnout in medical students: examining the prevalence and associated factors. South Med J. 2010;103(8): 758-63. https://doi.org/10.1097/SMJ.0b013e3181e6d6d4.

10. Bitran $M$, Zúñiga D, Pedrals N, Echeverría G, Vergara C, Rigotti A, et al. Burnout en la formación de profesionales de la salud en Chile: Factores de protección y riesgo, y propuestas de abordaje desde la perspectiva de los educadores. Rev Med Chil. 2019;147(4):510-7. https://doi.org/10.4067/S003498872019000400510 .

11. Chunming WM, Harrison R, Maclntyre R, Travaglia J, Balasooriya C. Burnout in medical students: a systematic review of experiences in Chinese medical schools. BMC Med Educ. 2017;17(1):217-28. https://doi.org/10.1186/s12909017-1064-3.

12. Liu H, Yansane Al, Zhang Y, Fu H, Hong N, Kalenderian E. Burnout and study engagement among medical students at Sun Yat-sen University, China. Med. 2018;97:15-21.

13. Hansell MW, Ungerleider RM, Brooks CA, Knudson MP, Kirk JK, Ungerleider JD. Temporal trends in medical student burnout. Fam Med. 2019;51(5):399404. https://doi.org/10.22454/FamMed.2019.270753.

14. Elkins C, Kyle P, Germain LJ. Burnout and depression in MS1 and MS3 years: a comparison of cohorts at one medical school. Famil. 2017:49:456-9.

15. Ludwig AB, Burton W, Weingarten J, Milan F, Myers DC, Kligler B. Depression and stress amongst undergraduate medical students. BMC Med Educ. 2015; 15(1):141-6. https://doi.org/10.1186/s12909-015-0425-Z

16. Bitran $M$, Torres-Sahli M, Echeverría $G$, Zúñiga $D$, Pedrals $N$, Rigotti $A$. Dispositional mindfulness -a protective factor for burnout in medical students? In: Abstract Book; 2018. p. 780.

17. Grace MK. Depressive symptoms, burnout, and declining medical career interest among undergraduate pre-medical students. Int J Med Educ. 2018; 9:302-8. https://doi.org/10.5116/ijme.5be5.8131.

18. Hojat M, Vergare $M$, Isenberg $G$, Cohen M, Spandorfer J. Underlying construct of empathy, optimism, and burnout in medical students. Int J Med Educ. 2015;6:12-6. https://doi.org/10.5116/ijme.54c3.60cd.

19. Brazeau CMLR, Schroeder R, Rovi S, Boyd L. Relationships between medical student burnout, empathy, and professionalism climate. Acad Med. 2010; 85(10 SUPPL):s33-6. https://doi.org/10.1097/ACM.0b013e3181ed4c47.

20. Zenasni F, Boujut E, Buffel C, Catu-pinault A, Tavani JL, Rigal L, et al. Development of a French-language version of the Jefferson scale of physician empathy and association with practice characteristics and burnout in a sample of general practitioners the Jefferson scale of physician. Int J Pers Cent Med. 2012;2:759-66.

21. Dyrbye LN, Thomas MR, Huntington JL, Lawson KL, Novotny PJ, Sloan JA, et al. Personal life events and medical student burnout: a multicenter study. Acad Med. 2006;81(4):374-84. https://doi.org/10.1097/00001888-20060400000010.

22. Bianchi R, Schonfeld IS, Laurent E. Physician burnout is better conceptualised as depression. Lancet. 2017;389(10077):1397-8. https://doi. org/10.1016/S0140-6736(17)30897-8.

23. Heinemann LV, Heinemann T. Burnout research: Emergence and scientific investigation of a contested diagnosis. SAGE Open. 2017;7:1-12. https://doi. org/10.1177/2158244017697154. 
24. Laurent E, Schonfeld IS, Bianchi R. Is a meta-analytic approach to burnout's prevalence timely? Psycho-Oncol. 2018;27(4):1355. https://doi.org/10.1002/ pon. 4665 .

25. Kristensen TS, Borritz M, Villadsen E, Christensen KB. The Copenhagen burnout inventory: a new tool for the assessment of burnout. Work Stress. 2005;19(3):192-207. https://doi.org/10.1080/02678370500297720.

26. Obregon M, Luo J, Shelton J, Blevins T, MacDowell M. Assessment of burnout in medical students using the Maslach burnout inventory-student survey: a cross-sectional data analysis. BMC Med Educ. 2020;20(1):376. https://doi.org/10.1186/s12909-020-02274-3.

27. Shi Y, Gugiu PC, Crowe RP, Way DP. A Rasch analysis validation of the Maslach burnout inventory-student survey with preclinical medical students. Teach Learn Med. 2019;31(2):154-69. https://doi.org/10.1080/104 01334.2018.1523010.

28. Faye-Dumanget C, Carré J, Le Borgne M, Boudoukha PAH. French validation of the Maslach burnout inventory-student survey (MBI-SS). J Eval Clin Pract. 2017;23(6):1247-51. https://doi.org/10.1111/jep.12771.

29. Dyrbye LN, Burke SE, Hardeman RR, Herrin J, Wittlin NM, Yeazel M, et al. Association of clinical specialty with symptoms of burnout and career choice regret among US resident physicians. JAMA. 2018;320(11):1114-30. https://doi.org/10.1001/jama.2018.12615.

\section{Publisher's Note}

Springer Nature remains neutral with regard to jurisdictional claims in published maps and institutional affiliations.

Ready to submit your research? Choose BMC and benefit from:

- fast, convenient online submission

- thorough peer review by experienced researchers in your field

- rapid publication on acceptance

- support for research data, including large and complex data types

- gold Open Access which fosters wider collaboration and increased citations

- maximum visibility for your research: over $100 \mathrm{M}$ website views per year

At $\mathrm{BMC}$, research is always in progress.

Learn more biomedcentral.com/submissions 